\title{
Prevalence of HBV infection in immunocompromised patients on ART nearly equals HBV mono infection in individuals not infected with HIV, Shimla Northern India
}

\author{
Aarti Garg*, Vineeta Sharma, Santwana Verma, Digvijay Singh, Anil Kanga, Balraj Singh \\ From 2nd International Science Symposium on HIV and Infectious Diseases (HIV SCIENCE 2014) \\ Chennai, India. 30 January - 1 February 2014
}

\section{Background}

It is estimated that $5 \%$ of the global population is chronically infected with HBV. The rate of HBV-HIV co infection is $10-20 \%$ in countries with HBV endemicity. The present study was undertaken to examine the HBV prevalence and HBV-HIV co infection at tertiary care institute, Northern India.

\section{Methods}

This is a retrospective study for the duration of five years, 2008-13. The HBV infection was detected using HBsAg (Hepatitis B surface antigen) and HIV/AIDS cases were screened as per NACO, 2007 criteria.

\section{Results}

A total of 10,134 cases were screened for detection of HBV infection and among these 1650(16.3\%) were receiving ART (anti retroviral therapy) while HIV status was not divulged in $8484(83.7 \%)$. HBsAg positive in $324 / 10134$ (3.20\%) cases, out of these HBV mono infection was seen in 264 (2.6\%) and co- infection with HIV in $60(0.6 \%)$. The concomitant HIV infections were seen in $3.64 \%$ (95 \%confidence interval 2.8-4.7) while in HBV mono infections were in $3.1 \%$ (95\% confidence interval 2.8-3.4). There is no statistical difference among the two groups ( $p$ value $>0.05$ ). Among the pediatric age group $0.95 \%$ had concomitant HIV infections as against 5.2\% with HBV infection alone. The mean age of presentation was 40.39 years. Males had higher prevalence rate of co infection (4.5:1).

\footnotetext{
* Correspondence: aartidewan.79@gmail.com

Indira Gandhi Medical College (IGMC), Shimla, Himachal Pradesh, India
}

\section{Conclusion}

Nearly identical prevalence of HBV infection irrespective of HIV infection strongly indicates HIV screening for Hepatitis B infected patients. The presence of undetected co infection shall result in missed cases, incomplete or partial treatment and suboptimal clinical follow up.

Published: 27 May 2014

doi:10.1186/1471-2334-14-S3-P26

Cite this article as: Garg et al:: Prevalence of HBV infection in immunocompromised patients on ART nearly equals HBV mono infection in individuals not infected with HIV, Shimla Northern India. BMC Infectious Diseases 2014 14(Suppl 3):P26.

Submit your next manuscript to BioMed Central and take full advantage of:

- Convenient online submission

- Thorough peer review

- No space constraints or color figure charges

- Immediate publication on acceptance

- Inclusion in PubMed, CAS, Scopus and Google Scholar

- Research which is freely available for redistribution 